\title{
The State of the Art in Family Therapy Research: What Works? How it Works?
}

\author{
Margarida Vilaça, Ana Paula Relvas \\ Faculty of Psychology and Educational Sciences of University of Coimbra, Portugal \\ Correspondence: Margarida Vilaça, Faculty of Psychology and Educational Sciences of University of Coimbra, \\ Portugal.
}

Received: November 14, 2013 Accepted: December 1, 2013 Available online: January 25, 2014

doi:10.11114/ijsss.v2i2.281

URL: http://dx.doi.org/10.11114/ijsss.v2i2.281

\begin{abstract}
Despite the growing popularity of systemic family therapy, little is known about the way in which therapeutic change occurs. This question concerns theorists and clinicians, and can only be answered through research focused not only on the results but also on the therapeutic process. This article presents an overview of the literature regarding the path followed by published research in systemic family therapy, in order to understand the methodological issues at the core of the current state of the art. Aiming to synthesize and integrate the relevant knowledge consolidated to date, a bibliographic review was carried out using electronic databases (e.g. EBSCO Host) and referenced books in the field of family therapy, with an emphasis on the most relevant meta-analysis and systematic revision studies. The observed predominance of studies regarding family therapy effectiveness over research on the therapeutic process is examined, and the main factors empirically associated to the therapeutic change are presented, emphasizing the fact that this investigation is based on the individual's perspective, rather than on the family perspective. Finally, new ways to successfully introduce specific factors in systemic family therapy are suggested, indicating the need to research these possibilities.
\end{abstract}

Keywords: systemic family therapy; research; methodology; outcomes; process.

\section{Introduction}

Over the last few years the health systems, specially the mental health system, have been pressured to prioritize empirically validated techniques and practices. Systemic family therapy (SFT) in particular has been accused of neglecting research, and has been strongly challenged to prove the effectiveness of its interventions (Carr, 2009a, 2009b; Larner, 2004; Stratton, 2011). Within such framework, it was inevitable that systemic therapists and researchers would work together for that goal, in order to scientifically fundament the rightness of family therapy funding as an integral part of mental health services (Carr, 2009a, 2009b). As a result, this alliance has recently allowed systemic therapy to acquire significant visibility in the mental health field, having proven its capacity against various relational problems and difficulties, such as domestic violence, anxiety, alcoholism, depression, etc. (Carr, 2009a, 2009b; Pinsof \& Wynne, 2000; Shadish \& Baldwin, 2003; Sprenkle, 2012; Stratton, 2011), and having been considered less expensive when compared to alternative and equally effective treatments (Stratton, 2011) or even as cost effective as other mental health groups (Moore, Hamilton, Crane, \& Fawcett, 2011).

On the other hand, the emergence of such balance between clinical practice and science managed to bring answers to family therapists and clients about the results of therapy and how change would occur (Burck, Frosh, Strickland-Clark, \& Morgan, 1998; Friedlander, Wildman, Heatherington, \& Skowron, 1994). As stated by Burck et al. (1998), the large volume of studies carried out regarding the therapy's effectiveness/non effectiveness concerned researchers and therapists with key questions about the way in which change occurs during therapy. Despite the increasing number of publications on this specific issue, little is known about why family therapy is effective, i.e., what works and how it works in family therapy (Friedlander et al., 1994; Kazdin, 2001; Sprenkle, 2012). Moreover, existing arguments for the fact that some models produce change are rarely proven in a solid scientific way, and a significant part of this work is much more reliant on intuition and empiricism than science (Barker, 2000). Finally, an impressive body of studies constituting this path faces methodological limitations arising both from the object of study (joint therapy) and from the procedures used (Sanderson et al., 2009), which results in a lack of studies based on the point of view of families as a 
whole. In fact, it is nonetheless paradoxical that the route of family therapy research is focused on the analysis of the individual's perception, rather than on understanding the family's characteristics and relations (Lebow, 2013).

In sum, it can be said that the efforts made to subject this approach to scientific scrutiny have opened paths not only in research (showing areas of future studies and contributing to an evidence-based clinical practice) but also in clinical practice (proving the effectiveness of this type of intervention which relies on practice-based evidence) (Shadish \& Baldwin, 2003; Stratton, 2011). Kazdin (2001) highlight the fact that knowing the influence of certain aspects in therapy can be important at a theoretical as well as a practical level.

All such issues considered, in this paper we intend to look at the path followed by research in the context of systemic family therapy and couple therapy, focusing on 1) the methodological challenges inherent in this type of research, and 2) the importance and usefulness of describing the results obtained in therapy, together with the need to comprehend the therapeutic process with the objective of understanding which conditions contribute to its effectiveness.

\section{Boundaries of the Review}

This paper will focus on exploring the results of a comprehensive literature review about research conducted in the SFT field from two perspectives: outcomes and process. Initially, we started by reviewing the main studies regarding the effectiveness of SFT, followed by an analysis of the studies highlighting the factors more closely associated with the therapeutic change. We chose to select a sample of potentially relevant articles of systematic revision and meta-analysis, because they synthesize external evidence from multiple studies that were identified and studied based on appropriate criteria and explicit procedures. We also scrutinized and analyzed empirical studies, since these represent the next level of evidence. After recording the main findings of each retrieved article, we slated each one in a table for "inclusion" or "exclusion", based on their appropriateness to the topic (family therapy research). Finally, we coordinated the evidence gathered from the earlier stages in a systematic and comprehensive analysis of family therapy research. The structure of this paper does not arise exclusively from the bibliographic research made under the criteria referred above, but rather articulates its results with the most frequent issues debated on this topic. Therefore, the sections and sub-sections were defined in advance (Research framework in SFT, Methodological questions inherent to the study of family therapy, Studies on effectiveness, Therapeutic process analysis and Main limitations in SFT research) and research results were subsequently integrated.

The review mainly focused on recent published works (about 80\% of the reviewed literature was published after 2000), but it also considered other works (the oldest dates back to 1983), for a deeper approach of the original models. We conducted systematic searches on online databases (e.g., EBSCO Host), from publication date of 1983 to present, including terms as "family therapy" "family therapy research" "family therapy outcomes" "family therapy process" "common factors" and "systemic research methodology". Manual searching was also performed to identify references that were not picked up during the computer-based research. Our selection process resulted in a similar number of studies related to therapy outcomes and processes. Specifically, 3 references about "family therapy" were selected, along with 18 references about "family therapy outcome research", 14 relating to "family therapy process research" and, finally, 3 about "systemic research methodologies". Naturally, some of these references provided important information on more than one subject (for example, references about family therapy outcomes research, very often also clarify some aspects about process research and vice versa); however, for simplification purposes, we categorized them according to the paper's main theme. The global references selection constitutes an attempt to represent a sample of relevant studies, although we are aware that many other studies may be pertinent to this review.

\section{Research Framework in SFT}

We will now present an overview of the research in this topic through a representative, but not exhaustive, revision of the published work carried out in the last thirty years.

The analysis of 274 studies on the results of family and couple therapy (Sanderson et al., 2009) characterizes in general and current terms the empirical study carried out in this area, focusing on the following questions: most used methodological plans and the changes that such choice has suffered over the years; most studied clinical population; most researched problems; and the way in which the family and couple therapy outcomes have been evaluated. The results indicate that the most frequent research plan is the experimental one, followed by the pre-test/post-test without a comparison group and the quasi-experimental design. The analysis performed on the methodological plans adopted by the studies carried out between 1990 and 2005 shows a non-significant decrease in the use of the experimental plan in the nineties, followed by a significant increase in the late nineties and early two thousands. With regards to the target population, most studies developed in this area cover an adult population (60\%), followed by studies with teenagers $(23 \%)$ and children $(22 \%)$. The most frequently studied problems are equally varied, focusing on the following topics (in decreasing order of frequency): psychoactive substance use disorders, childhood disorders, marital difficulties, mood 
disorders and family difficulties. It should be noted that on the 274 studies revised, 480 result evaluation tools were identified, mostly multidimensional scales for individual evaluation.

\section{Methodological Questions Inherent to the Study of Family Therapy}

As previously noted, the methodological questions are rather relevant for this research topic. Considering that measurement is the main method for determining family therapy's effectiveness and processes, during the past three decades we have witnessed an exponential increase in the number of empirical studies and meta-analyses with good methodology regarding the systemic family interventions (Carr, 2009a; b; Larner, 2004; Shadish \& Baldwin 2003; Sprenkle, 2012; Von Sydow, Beher, Schweitzer, \& Retzlaff, 2010). Most recently, the importance of practice-based research and qualitative studies for evaluating the effectiveness of such interventions in general, and in family therapy in particular, has been debated (Larner, 2004; Popay, 2000, Sprenkle, 2012). Nevertheless, the legitimacy of those conclusions is directly related to the quality of the methods adopted within such deductions (Wood, Crane, Schaalje, \& Law, 2005; Larner, 2004; Sanderson et al., 2009). As it has been noted in other areas, family therapy has used several methods for producing knowledge about the effectiveness and the process of change in therapy, from quantitative to qualitative methods.

Specifically in SFT, the qualitative-interpretative method (content analysis, case study, Grounded Theory, for example) is a privileged path in the clinical process study, namely to formulate theoretical concepts from the participants' detailed descriptions (Sells, Smith, \& Sprenkle, 1999). These theoretical concepts are often transformed into hypotheses, which are then tested through quantitative methods (research, empirical studies, for example), the results of which indicate the validity (or not) of those same hypotheses. When these procedures are used in the same study and both methodologies are conjugated, the adopted model is mixed or multimethod (Sells et al., 1999). According to Sells et al. (1999), the multimethod model (combination of a variety of methodologies) is the most comprehensive for family therapy research, since it benefits from the potential of both methods and promotes the connection between theory, research and clinical practice. Specifically, the mixed methods research model (quantitative and qualitative research) seems to have much to offer to the SFT field since it allows therapists to understand both process of change and interventions evaluation (Gambrel \& Butler, 2013). However, the systemic researchers are still very conditioned by the traditional courses of investigation and have therefore been resisting the adoption of the mixed method or multimethod model. Although the benefits of the mixed methods model are evident to researchers, little is known about its use in family therapy investigation studies, which results in a lack of mixed methods studies in SFT overall (Gambrel \& Butler, 2013). In this study, we identified and selected only one mixed method study (Blow et al., 2009).

Before starting the family or couple therapy research process, it is important to enquire about the problems being investigated, in order to better select the methodological choices for research. It would also be important for researchers in this health field to incorporate qualitative methods with quantitative methods (the multimethod model) as much as possible, as this conjugation creates a suitable complementarity that would allow for a rich data collection and a more sustained result interpretation.

\section{Studies on Effectiveness}

To approach the SFT effectiveness studies, we chose to present a sample of studies deemed appropriate and representative of this point (Table 1).

Table 1. Summary of the results of the effectiveness studies analyzed

\begin{tabular}{|c|c|c|c|}
\hline Author(s) & Goal & Method & Conclusion \\
\hline $\begin{array}{l}\text { Carr, } \\
\text { 2009a, } \\
2009 b\end{array}$ & $\begin{array}{l}\text { To summarize scientific } \\
\text { evidence on systemic } \\
\text { interventions related to } \\
\text { specific problems of } \\
\text { childhood, adolescence } \\
\text { and adulthood. }\end{array}$ & $\begin{array}{l}\text { Research and analysis of various } \\
\text { meta-analysis studies, systematic revision } \\
\text { of literature and empirical studies on the } \\
\text { effectiveness of the systemic practice, } \\
\text { involving family members or members of } \\
\text { the family network in resolving the } \\
\text { problems of children and teenagers from } 0 \\
\text { to } 18 \text { years of age and youngsters or adults } \\
\text { over } 18 \text {. }\end{array}$ & $\begin{array}{l}\text { - Duly articulated systemic } \\
\text { interventions are effective with } \\
\text { many mental and relational } \\
\text { problems; } \\
\text { - The interventions analyzed are } \\
\text { brief, and can be practiced by a } \\
\text { variety of professionals in an } \\
\text { ambulatory context; } \\
\text { - Manuals have been developed } \\
\text { for systemic interventions, and } \\
\text { these can be used flexibly in } \\
\text { individual cases; }\end{array}$ \\
\hline
\end{tabular}


Lundband To investigate the Empirical and clinical study with a single and Hansson, 2006 effectiveness of couple grou therapy in a clinical context in Sweden. group of around 300 couples; the couples' elements completed an evaluation protocol regarding the gravity of their relational and individual problems and the individual resources before, after and two years after therapy. studies' outcomes relating to adults, for the context of health services;

- Most scientific evidence-based systemic interventions have been developed in accordance with the cognitive-behavioral, structural and strategic line of thought.

- Couple therapy shows effectiveness in the Swedish context;

- Only less than half of the 300 couples concluded therapy, and only $40 \%$ carried out the follow-up;

- Significant improvement was noticed in the relationship, individual mental health and coping capacity;

- The follow-up emphasizes that the results were maintained and, in some cases, improved.

Pinsof and To summarize research Revision of the 9 significant studies - There is scientific evidence to Wynne, developed so far (empirical and meta-analysis) about the show the effectiveness and 1995 regarding family effectiveness of family and couple therapy efficiency of SFT in treating many interventions. applied to specific problems with children, relational problems/disorders in teenagers and adults. specific populations;

- Lack of studies indicating negative effects of SFT;

- SFT is not enough in the treatment of many serious chronic mental illnesses.

Shadish To summarize the Research and analysis of 20 meta-analyses - The meta-analyses support and scientific results on the on the family and couple interventions family and couple therapy Baldwin, effects of family and published between 1987 and $2001 . \quad$ effectiveness in treating anguished 2003 couple therapy. couples and in enriching the family and couple;

- Small differences between the results obtained with family therapy and with couple therapy;

- In general terms, the interventions show a significant effectiveness of $40-50 \%$.

Von Sydow To analyze the systemic Research and meta-content analysis of 38 - Identification of 38 studies et al., 2010 therapy effectiveness in systemic therapy evaluation empirical published in English, German, the treatment of studies in various contexts (family, couple, Spanish and Chinese;

mental disorders in individual and multifamily group therapy). - From the total number, 34 adults. studies show a systemic therapy effectiveness with adults diagnosed with mental disorder in at least five groups;

- The results reached were maintained after a five-year follow-up. 
Pinsof and Wynne (1995) were pioneers in analyzing the effectiveness of family and couple therapy. After carrying out a literature revision study, the authors concluded that these two forms of therapy are more effective interventions than others which do not involve family members in treating schizophrenic adults, depressed women in a situation of marital crisis, adult alcoholism and psychoactive substance abuse, behavioral problems in teenagers, teenage psychoactive substance abuse, anorexia in young teenagers, childhood autism, aggression and non-fulfilment associated with attention deficit disorder and hyperactivity, dementia and cardiovascular problems. It was also noted that, both in family therapy and in couple therapy, these are more cost effective than the usual hospital treatment for adult schizophrenia and unipolar depression, as well as the residential treatment for teenagers with behavioral problems. Another conclusion was that both interventions are not sufficient when used exclusively in the treatment of some chronic and severe mental problems such as schizophrenia, bipolar and unipolar major affective disorder, drug abuse, autism and severe behavioral disorders, although they help the effectiveness of specific treatments for these disorders.

Another study carried out in Sweden (Lundblad \& Hansson, 2006) involved more than 300 couples, with the objective of verifying the effectiveness of couple therapy throughout time in this particular cultural context. At the beginning, the group studied presented serious difficulties in terms of marital functioning, interactions between the couple and psychiatric symptoms. The intervention results indicated that the therapy brought significant improvement to the relationship and the individual mental health, having also increased coping capacities. After a long-term follow-up, the authors confirmed that the couples that concluded therapy maintained their results and, in some aspects, the results improved for both genders.

In another important review of 20 meta-analyses about family and couple therapy (in a total of over 900 studies) applied to a great variety of mental health problems throughout the life cycle, Shadish and Baldwin (2003) concluded that, in the majority of cases, the results were more positive after therapy and after six to twelve-month follow-up than about 71 per cent of the control group families who, in the majority of cases, also benefited from other quality services. The authors also noticed small differences between couple therapy and family therapy, but in general terms about 40 to $50 \%$ of the clients reached clinically significant results.

Carr (2009a, 2009b) also developed important revision studies about family therapy and other systemic interventions (parental training, multi-systemic therapy, psychoeducational groups), collecting evidence of its effectiveness with children, teenagers and adults, and identifying the most effective types of family interventions for a variety of specific relational and mental health problems. These studies present conclusions that support the effectiveness of family therapy in families with children up to 18 years old who suffered childhood problems, neglect and childhood abuse, behavioral problems, emotional problems and somatization issues. Regarding the intervention with adults, the studies showed positive evidence with relationship distress, psychosexual problems, domestic violence, anxiety disorders, mood disorders, alcoholism, schizophrenia and chronic physical disease.

More recently, Von Sydow et al. (2010) analyzed the content of 38 empirical essays about the effectiveness of systemic therapy (family therapy, couple therapy, group therapy, for example) with adults, concluding that 34 of these studies attested the effectiveness of such interventions, mainly in the treatment of mood disorders, eating disorders, drug abuse problems, mental and social issues associated to medical conditions and physical problems, and schizophrenia. In this study, the authors also concluded that (i) systemic therapy has no adverse effects; (ii) with certain disorders systemic therapy needs to be combined with other psychotherapeutic or pharmacological forms of intervention; (iii) the number of drop-outs in this practice is lower than in other forms of psychotherapy; (iv) the most efficient interventions involved guidance to strengths/resources and positive reframing.

In general terms, the studies carried out to verify the results of family and couple therapy, mainly in the U.S., clearly indicate the effectiveness of both interventions in a variety of problems with children, teenagers and adults.

\section{Therapeutic Process Analysis}

The concern with the rigor of therapy in general, including family therapy, together with an emphasis in explaining outcomes, led to an accentuation of the importance of the factors associated with the therapy(ie)s' success. Initially, the paradigm of therapeutic change considered the models and techniques as the only aspects responsible for the process of change. This exclusivity was later challenged by a group of authors who presented the common factors paradigm (Sprenkle, Davis, \& Lebow, 2009). Since the end of the thirties, the concern to identify the key elements that make different interventions (in terms of models and techniques) effective has been increasing, with a view to understanding which therapeutic factors are most common (Sexton, Ridley, \& Kleiner, 2004). According to this last paradigm, the success of therapy does not depend mainly on the specific contributions of each model or theoretical approach, it rather depends on a number of factors or mechanisms of change which are common in the different forms of effective therapy, and the models are considered as a background in which the common factors operate (Hubble, Duncan, \& Miller, 2006; Sexton et al., 2011; Sprenkle et al., 2009). With this approach in mind, we will present some elements, which are widely identified as relevant for the therapeutic process in general, and, therefore, also for SFT. 


\subsection{Client}

Within the group of common factors, the ones relating to the client are considered the most recurrent and relevant (Hubble et al., 2006; Sprenkle et al., 2009; Sprenkle \& Blow, 2004), and are responsible for about $40 \%$ of therapeutic change, as indicated by studies carried out by Lambert (1992) on the importance of common factors for the psychotherapy outcomes. In fact, the client factors are related to the client's characteristics or qualities that influenced the therapeutic change (Blow et al., 2009) or, in other words, everything that the client brings to the context of therapy which is important in their daily life. This group of factors integrates the client's static (gender, age or sexual orientation) and non-static (individual learning styles, family cohesion or persistence) characteristics, the former being significantly more studied that the latter (Sprenkle \& Blow, 2004).

The most recent studies have been concerned with non-static characteristics related to motivation and involvement in treatment (Hubble et al., 2006). We can state that in the case of SFT, this kind of client characteristic is the most difficult to research, particularly in empirical terms, because it implies the need to evaluate and measure the family as a whole, which is difficult and carries the risk of data distortion when we think of the measurement commonly used in individual therapies (personality questionnaires, for example). In SFT, this goal will require complex studies, often recurring to highly advanced mixed methodologies and statistical procedures (multi-level analyses, for example).

Nevertheless, in fundamentally theoretical and clinical terms, it is possible to highlight some aspects of the family dynamics which should be investigated in this context as intervening client factors in the process of change, namely the family functioning, the family life cycle stage, the family quality of life and family coping.

Taking the example of family life cycle, it was prematurely stated that the transition from one stage to another creates a state of crisis in the family, strongly shaking the stability of family life, allowing its development, but also its possible malfunction (Carter \& McGoldrick, 1995; Olson et al., 1983). Thus, the specificity of each family life cycle period, as well as the transformations undergone during stage transition, are identified as possible inhibitors or facilitators of family change (Friedlander, Escudero, \& Heatherington, 2006; Olson et al. 1983). However, as far as we know, there is no empirical data regarding the impact of the family's developmental stage in the therapeutic process, which brings us to the issue of finding out if the families are more (/less) susceptible to change in certain stages of their life cycle. Equally, the transition from one life cycle stage to a more complex one implies, as can be predicted, some degree of stress, since it requires the occurrence of real change in the relationship patterns. Theoretically, one can expect the families with more strengths and skills to better mobilize resources and more effectively overcome difficulties in a moment of crisis (Olson et al., 1983). Family coping resulting from individual responses, which emerge when the family system in a crisis has to renegotiate new family rules (Carter \& McGoldrick, 1995; Olson et al., 1983; Vilaça \& Relvas, 2009), has therefore an important role in the process of change.

Lastly, the family quality of life is directly associated with the type of strategies used by the family in overcoming the stress to which it is exposed. According to a study carried out by Olson and collaborators (1983) in which a subjective evaluation was made on the quality of life, families who describe themselves as very satisfied tend to use a greater number of coping strategies and experience low levels of stress, showing a greater level of resistance to stressing events in life. More recently, a study developed by Vilaça and Relvas (2009) reinforces these conclusions, indicating that families with a better quality of life are also those who use a greater number of resources and are more resistant to family stress.

In spite of the difficulties found in longitudinal studies, it would be important to empirically study if the therapeutic change varies according to the life cycle stage of the family being followed, and whether this change is associated to coping strategies and family quality of life.

\subsection{Therapeutic Relationship}

Even though initially the therapeutic process research was focused on the study of the therapist's characteristics, which contributed to a therapeutic relationship (such as empathy and kindness), the interest quickly shifted to the study of the therapeutic relationship with a focus, in this context, on the variable of therapeutic alliance. Within SFT, this is also the most investigated common factor (Sprenkle \& Blow, 2004). The results accumulated since the eighties regarding the connection between therapist and client, and its effect on the therapeutic outcomes, allow us to state that the most solid evidence relating process and outcomes in systemic therapy is the relationship between clients and therapist, specifically the therapeutic alliance (Friedlander et al., 2006; Friedlander et al., 1994; Hubble et al., 2006).

A meta-analysis study about the influence of the therapeutic relationship variables on the results of family therapy with children and teenagers (Karver, Handelsman, Fields, \& Bickman, 2006) reveals that, in general terms, the 29 constructs analyzed (alliance, empathy, goal consensus, collaboration, resistance, congruence, expectations and preferences, involvement, comfort, participation, among others), grouped into different categories (therapist's interpersonal skills, therapist's self-disclosure, therapist's direct influence skills, therapeutic relationship with the youth client, therapeutic 
alliance with the youth client, affect towards the therapist, youth client's willingness to participate, client's autonomy, youth client's participation, therapeutic relationship with the parents, parents' willingness to participate, parents' participation and therapeutic alliance with the family) are moderately to strongly associated with the therapy outcomes. The best predictors of therapeutic success are the therapist's direct influencing skills, the therapeutic relationship with the youth client, the therapist's interpersonal skills, the youth client's willingness to participate, the parents' willingness to participate, the youth client's participation and the parents' participation in therapy. The remaining categories have a low to moderate connection with the therapeutic outcomes, except the therapist's self-disclosure, which did not show a connection with the treatment outcomes. The results also highlighted that certain behaviors from the therapist, such as empathy or enthusiasm, have important implications in the outcomes of therapy involving children and teenagers.

The relevance of therapeutic alliance as a common explanatory factor for a considerable part of the therapy outcomes, in general, has been confirmed - between 22\% and 26\% (Ribeiro, 2009); 30\% (Lambert, 1992) - however, there is some controversy around the objective conceptual clarification of this construct throughout its history, namely due to the fact that its importance is recognized by different theoretical approaches (psychodynamic, humanist, behavioral and cognitivist), which proves its cross-sectional character (Ribeiro, 2009). Specifically within the systemic approach, the therapeutic alliance is distinguished by the bidirectional relationship between therapist(s) and client(s) and by the notion of collaboration (Friedlander et al., 2006; Ribeiro, 2009). In any case, it has become essential to create instruments for evaluating therapy alliance, seen as collaboration within the relationship developed between the therapist and the clients in the therapeutic process (Friedlander et al., 2006; Ribeiro, 2009). According to Friedlander et al. (2006), the therapeutic alliance in family therapy involves an intrapersonal dimension, which can be studied through self-response instruments, and an interpersonal dimension, which can be analyzed through observational methods. This being so, the authors created the System for Observing Family Therapy Alliances (SOFTA; Friedlander et al., 2006), which was the result of the empirical work in the development and validation of observational (SOFTA-o) and self-report (SOFTA-s) instruments, created to evaluate the strength of alliance in family and couple therapy. Both versions were developed based on a transtheoretical model which contemplates four dimensions, translating this construct in the context of therapy: Engagement in the Therapeutic Process, Emotional Connection to the Therapist, Safety within the Therapeutic System and Shared Sense of Purpose within the Family (Friedlander et al., 2006; Relvas et al., 2010). The two SOFTA versions were shown to be important indicators of therapeutic process, its use being supported in research, training and supervision (Friedlander et al., 2006).

Trying to understand the therapeutic process, Escudero, Friedlander, Varela and Abascald (2008) carried out a study with 37 families, in which the observed therapeutic alliance (using SOFTA-o) and the therapy outcomes were compared. The authors identified a positive connection between the clients' behavior in session, their perception of therapeutic alliance and the progress in therapy. They also concluded that the positive outcomes (consensually identified by the therapists and family members as a general improvement and a reduction of the problem's gravity) were significantly predicted by the various therapeutic alliance dimensions.

\subsection{Expectations}

This factor is connected to a parcel of the therapeutic success which is justified by the clients' and therapists' perception of therapy, i.e., it is related to the feeling that change is actually possible and the belief that the therapy is effective and credible (Blow et al., 2009; Hubble et al., 2006; Sprenkle \& Blow, 2004; Tambling, 2012). As clients and therapists interact during the therapeutic process, change comes from the hope and positive expectations that they have throughout the sessions. In sum, hope, as an element associated to change in the context of SFT, is related to the clients' and therapists' beliefs, expectations and commitment to the therapy (Tambling, 2012), accounting for $15 \%$ of the therapeutic change (Lambert, 1992).

Although few specific studies exist on the aspects of hope and expectations, the empirical studies carried out in the nineties regarding credibility suggest that the therapists' capacity for presenting therapy consistently and in accordance with the clients' expectations clearly contributes to the success of the treatment's results (Sprenkle \& Blow, 2004). Existing evidence also suggests that positive expectations are related to the initiation and maintenance of treatment, alliance establishment and therapy outcomes (Tambling, 2012).

\subsection{Model / Techniques}

The therapeutic process component related to model and techniques consists of the therapist's theoretical orientation, the therapeutic methods and the strategies implemented in order to impel the client for action, with a view to improve the situation that led to therapy (Hubble et al., 2006). It relates to the beliefs and procedures of each specific intervention, for example the use of genograms in Bowenian family therapy, the use of systematic desensitization in cognitive-behavioral therapies or the use of hypnosis in psychoanalysis (Hubble et al., 2006). Just like the previous factor, the model and techniques contribute in about 15\% for the success of therapy in general (Lambert, 1992). 


\section{Main limitations in SFT Research}

In general terms, the limitations found both in the meta-analysis and the empirical studies relate to methodological issues. As far as the meta-analysis studies are concerned, the predominant limitations are those associated with the heterogeneity of methodologies used in the various studies, where it proved common to combine studies using diversified evaluation measurements (Von Sydow et al., 2010). Also, the fact that meta-analyses involve a great number of researchers in the process of data collection and analysis may compromise the conclusions, since it can cause discrepancies in data quotation (Sanderson et al., 2009). On the other hand, in some studies regarding the process and outcomes of therapy, the existence of one single informant for both assessments limits the validity of the results, because the connection between the outcomes and the therapy process may be inflated by the shared variance of the respondent (Karver et al., 2005). Another limitation has to do with the fact that some investigations analyzed were not published in scientific journals (Karver et al., 2005). Finally, the majority of the meta-analyses did not review all studies published about the topic, only the ones integrated in a number of journals or during a predefined timeframe (Sanderson et al., 2009).

With regards to the empirical studies, the main difficulty found was the large number of drop-outs at the post-intervention evaluation stage, which in fact is a common aspect in psychotherapy research (Lundband \& Hansson 2006). In the topic of the correct conduction of research regarding SFT effectiveness, Pinsof and Wynne (2000) highlight six main criteria: to occur in a laboratorial clinical setting; to cover a psychiatric problem or disorder clearly definable; to involve at least two groups (an experimental group undergoing intervention and a control group not undergoing treatment or undergoing an alternative treatment); to randomly select clients for both groups; the treatment needs to be specified and conducted by manuals, monitoring the therapist's work throughout the study; the clients must be measured in at least two different moments (pre and post intervention) with standardized measurements. A large portion of the empirical studies conducted, namely regarding SFT, does not follow these criteria (Pinsof \& Wynne, 2000; Carr, 2009a).

Apart from the restrictions identified by the authors, it is clear that, in general terms, most research on SFT lacks follow-up studies to confirm the long-term maintenance of the outcomes. Furthermore, the risk of linearly conducting treatment, as well as methods and analysis, is greater in the context of research. When performing a macro analysis on the fragilities of an SFT study, it is inevitable to highlight the fact that each family experiences therapy differently, a fact rarely perceivable in science and particularly in quantitative empirical studies.

\section{Conclusions and Suggestions for Future Research Directions in SFT}

Over the last 10 years, significant progress has been achieved in the empirical study of SFT effectiveness (likely to improve with research), attesting its effective action in a variety of psychological difficulties.

Methodologically, the adoption of the quantitative and/or the qualitative method has originated a necessary tension, since both methodologies share an investigative, ethical and pragmatic curiosity about what is useful in the arduous task of therapy. The multimethod bidirectional model, specifically the mixed method research, is recognized by some authors as the most adequate in the case of systemic complexity, but it has been slow and difficult to get scientific attention. Nevertheless, the use of mixed method research continues to grow, especially to study systems, showing its potential in combining the clients/therapists perspective to experimental research (Gambrel \& Butler, 2013).

Currently, the most common form of SFT effectiveness evaluation is meta-analysis (Stratton, 2005). However, the great majority of these publications either proves the effectiveness of the systemic intervention or identifies the most effective treatment for specific problems in children, teenagers and adults.

In terms of studying the therapeutic process, there is an unlimited number of variables associated to change in therapy, as well as various explanations for the fact that therapy works, although they are rarely empirically validated. Additionally, little theory and research has been dedicated to the process of therapeutic change in the family context, the emphasis being on analyzing the individual level (self- centered reports).

Having authenticated the strength of the factors which are transversal to the different therapies in therapeutic change, it is now urgent to empirically validate certain assumptions related to family diversity and dynamics which the theoretical references and the clinical practice connect with the therapeutic process (such as the family life cycle, family coping and family life quality), in order to ascertain if their contribution is, in effect, significant to the therapeutic process and, if so, in which way.

Despite the consistency of results across the studies here analyzed, there are limitations that should be considered. This review cannot be considered exhaustive specially because we did not review all SFT outcome and process studies published in the period between 1983 and 2013, but we analyzed and selected studies that report the majority of available SFT outcome and process studies (for example, by selecting meta-analyzes published studies). Additionally, we focused mostly on U.S. and U.K. journals (with the exception of Mosaico, based in Spain). Finally, the presented review conjugates rigorous meta-analysis with more descriptive surveys of the evidence. 
In SFT, the therapeutic process is clearly complex: a "multiple" client, often including more than one request for help. These demands are often different or even opposed, and the same happens with the expectations and individual characteristics of the family/couple's members and the therapist(s). Consequently, research in this area also needs to be complex. In sum, in order to answer the question "what works and how it works" in SFT, the future development of research must, as much as possible, be based on mixed methodology studies (qualitative and quantitative) and adopt a diachronic approach (data collection at different moments), using multimethod procedures (observational and self-report measurements) and multi-informants (perspective of the therapist, the clients, the extended family and the external observers). Finally it should enable the interconnection of outcomes and process measures. Accepting the theory of common factors, besides the methodological issues referred above, SFT's outcomes and process future research must include the client's dynamic factors (family life cycle stage, family functioning and so) as the utmost important variable.

\section{References}

Barker, P. (2000). Fundamentos da terapia familiar. Lisboa: Climepsi Editores.

Blow, A. J., Morrison, N. C., Tamaren, K., Wright, K., Schaafsma, R., \& Nadaud A. (2009). Change processes in couple therapy: an intensive case analysis of one couple using a common factors lens. Journal of Marital and Family Therapy, 35, 350-368. http://dx.doi.org/10.1111/j.1752-0606.2009.00122.x

Burck, C., Frosh, S., Strickland-Clark, L., \& Morgan, K. (1998). The process of enabling change: A study of therapist interventions in family therapy. Journal of Family Therapy, 20, 253-267. http://dx.doi.org/10.1111/1467-6427.00086

Carr, A. (2009a). The effectiveness of family therapy and systemic interventions for adult-focused problems. Journal of Family Therapy, 31, 46-74. http://dx.doi.org/10.1111/j.1467-6427.2008.00452.x

Carr, A. (2009b). The effectiveness of family therapy and systemic interventions for child-focused problems. Journal of Family Therapy, 31, 3-45. http://dx.doi.org/10.1111/j.1467-6427.2008.00451.x

Carter, B., \& McGoldrick, M. (1995). As Mudanças no Ciclo de Vida Familiar. Uma estrutura para a terapia familiar. Porto Alegre: Editora Artes Médicas.

Escudero, V., Friedlander, M., Varela, N., \& Abascald, A. (2008). Observing the therapeutic alliance in family therapy: associations with participants' perceptions and therapeutic outcomes. Journal of Family Therapy, 30, 194-214. http://dx.doi.org/10.1111/j.1467-6427.2008.00425.x

Friedlander, M., Escudero, V., \& Heatherington, L. (2006). Therapeutic Alliances in Couple and Family Therapy: An Empirically Informed Guide to Practice. Washington, DC: American Psychological Association.

Friedlander, M., Wildman, J., Heatherington, L., \& Skowron, E. A. (1994). What we do and don't know about the process of family therapy. Journal of Family Psychology, 8, 390-416.

Gambrel, L., \& Butler, J. (2013). Mixed methods research in marriage and family therapy: A content analysis. Journal of Marital and Family Therapy, 39(2), 163-181. http://dx.doi.org/10.1111/j.1752-0606.2011.00260.x

Hubble, M., Duncan, B., \& Miller, S. (2006). The heart and soul of change: What works in therapy. Washington: American Psychological Association Press.

Karver, M. S., Handelsman, J. B., Fields, S., \& Bickman, L. (2006). Meta-analysis of therapeutic relationship variables in youth and family therapy: The evidence for different relationship variables in the child and adolescent treatment outcome literature. Clinical Psychology Review, 26, 50-65. http://dx.doi.org/10.1016/j.cpr.2005.09.001

Kazdin, A. (2001). Progression of family therapy research and clinical application of treatment require better understanding of the change process. Clinical Psychology, 8, 143-151. http://dx.doi.org/10.1093/clipsy.8.2.143

Lambert, M. J. (1992). Implications of outcome research for psychotherapy integration. In J. C. Norcross, \& M. R. Goldfried (Eds.), Handbook of Psychotherapy Integration (pp.94-129). New York: Basic Books.

Larner, G. (2004). Family therapy and the politics evidence. Journal of Family Therapy, 26, 17-39. http://dx.doi.org/10.1111/j.1467-6427.2004.00265.x

Lebow, J. L. (2013). Editorial: DSM-V and Family Therapy. Family Process, 52(2), 155-160. http://dx.doi.org/10.1111/famp.12035

Lundband, A. M., \& Hansson, K. (2006). Couples therapy: effectiveness of treatment and long-term follow-up. Journal of Family Therapy, 28, 136-152. http://dx.doi.org/10.1111/j.1467-6427.2006.00343.x

Moore, A., Hamilton, S., Crane, D., \& Fawcett, D. (2011). The influence of professional license type on the outcome of family therapy. The American Journal of Family Therapy, 39(2), 149-161. http://dx.doi.org/10.1080/01926187.2010.530186 
Olson, D. H., McCubbin, H. I., Barnes, H. L., Larsen, A. S., Muxen, M. J., \& Wilson, M. A. (1983). Families: What makes them work? Beverly Hills: Sage Publications.

Pinsof, W. M., \& Wynne, L. C. (1995). The efficacy of marital and family therapy: An empirical overview, conclusions and recommendations. Journal of Marital and Family Therapy, 21, 585- 613.

Pinsof, W. M., \& Wynne, L. C. (2000). Towards progress research: closing the gap between family therapy practice and research. Journal of Marital and Family Therapy, 26, 1-8. http://dx.doi.org/10.1111/j.1752-0606.2000.tb00270.x

Popay, J. (2000). Cochrane/ Campbell Qualitative Methods Groups. The Cochrane Collaboration. Retrieved from http://www.salford.ac.uk/iphrp/cochrane

Relvas, A. P., Escudero, V., Sotero, L., Cunha, D., Portugal, A., \& Vilaça, M. (2010). The System for Observing Family Therapy Alliances (SOFTA) and the preliminary Portuguese studies. European Family Therapy Association. Retrieved from http://www.europeanfamilytherapy.eu/wp-content/uploads/2012/10/softa.pdf

Ribeiro, E. (2009). Aliança Terapêutica: Da Teoria à Prática Clínica. Braga: Psiquilibrios Edições.

Sanderson, J., Kosutic, I., Garcia, M., Melendez, T., Donoghue, J., Perumbilly, S., Franzen, C., \& Anderson, S. (2009). The measurement of outcome variables in couple and family therapy research. The American Journal of Family Therapy, 37, 239-257. http://dx.doi.org/10.1080/01926180802405935

Sells, S., Smith, T., \& Sprenkle, D. (1999). Integrating qualitative and quantitative research methods: A research model. Family Process, 34, 199-218. http://dx.doi.org/10.1111/j.1545-5300.1995.00199.x

Sexton, T., Gordon, K., Gurman, A., Lebow, J., Holtzworth-Munroe, A., \& Johnson, S. (2011). Guidelines for classifying evidence-based treatments in couple and family therapy. Family Process, 50(3), 377-392. http://dx.doi.org/10.1111/j.1545-5300.2011.01363.x

Sexton, T., Ridley, C., \& Kleiner, A. (2004). Beyond common factors: Multilevel process models of therapeutic change in marriage and family therapy. Journal of Marital and Family Therapy, 30, 131-149. http://dx.doi.org/10.1111/j.1752-0606.2004.tb01229.x

Shadish, W., \& Baldwin, S. (2003). Meta-analysis of MFT interventions. Journal of Marital and Family Therapy, 29, 547-570. http://dx.doi.org/10.1111/j.1752-0606.2003.tb01694.x

Sprenkle, D. (2012). Intervention research in couple and family therapy: A methodological and substantive review and an introduction to the special issues. Journal of Marital and Family Therapy, 38, 3-29. http://dx.doi.org/10.1111/j.1752-0606.2011.00271.x

Sprenkle, D., \& Blow, A. (2004). Common factors and our sacred models. Journal of Marital and Family Therapy, 30, 113-129. http://dx.doi.org/10.1111/j.1752-0606.2004.tb01228.x

Sprenkle, D., Davis, S., \& Lebow J. (2009). Common Factors in Couple and Family Therapy: The Overlooked Foundation for Effective Practice. New York: Guilford.

Stratton, P. (2005). Report on the evidence base of systemic family therapy. United Kingdom: Association for Family Therapy.

Stratton, P. (2011). The evidence base of systemic family and couples therapies. United Kingdom: Association for Family Therapy.

Tambling, R. (2012). A literature review of therapeutic expectancy effects. Contemporary Family Therapy, 34, 402-415. http://dx.doi.org/10.1007/s10591-012-9201-y

Vilaça, A., \& Relvas, A. P. (2009). Vulnerabilidade ao stress, coping, qualidade de vida e ciclo vital da família. Mosaico, $43,12-24$.

Von Sydow, K., Beher, S., Schweitzer, J., \& Retzlaff, R. (2010). The efficacy of systemic therapy with adult patients: A meta-content analysis of 38 randomized controlled trials. Family Process, 49, 457-485. http://dx.doi.org/10.1111/j.1545-5300.2010.01334.x

Wood, N., Crane, R., Schaalje, B., \& Law, D. (2005). What works for whom: A meta-analytic review of marital and couples therapy in reference to marital distress. The American Journal of Family Therapy, 33, 273-287. http://dx.doi.org/10.1080/01926180590962147

\section{(cc) $\mathrm{Br}$}

This work is licensed under a Creative Commons Attribution 3.0 License. 